\title{
Acute management of alcohol and other drug problems
}

\author{
Emma K Brandish \\ Christopher T Owen \\ Julia Sinclair
}

Emma K Brandish BSc BM MRCPsych is Academic Clinical Fellow in General Adult Psychiatry, Wessex Deanery, UK. Competing interests: EKB is supported by the University of Southampton, National Institute of Health Research Academic Clinical Fellowship programme.

Christopher T Owen MChem BM MRCP (UK) is a GP Trainee, Wessex Deanery, UK. Competing interests: none declared.

Julia Sinclair MB BS MRCPsych DPhil is Associate Professor of Psychiatry, University of Southampton Honorary Consultant in Alcohol Liaison, University Hospital Southampton, UK. Her primary research aim is to conduct clinically relevant research in patients with alcohol use disorders, specifically to investigate how biological, psychological and social mechanisms interact in this group, and their impact on clinical outcomes in terms of prevention, engagement and response to treatment. Competing interests: JMAS was part of the international advisory board for Lundbeck A/S for nalmefene until 2015.

\section{Abstract}

Intoxication and withdrawal syndromes are common presentations in acute medicine. A comprehensive history, including a collateral one, and thorough examination looking for patterns of signs and symptoms, backed by appropriate investigations, forms the basis of good management. A collaborative, empathic and non-judgemental approach that recognizes the patient's distress, explains the goals of management and sets clear boundaries significantly reduces potential complications and improves outcomes. An understanding of the pharmacology and clinical effects of alcohol, benzodiazepines, opioids and stimulants is essential to accurately diagnose and manage patients who may not be able to give an accurate history.

\section{Keywords}

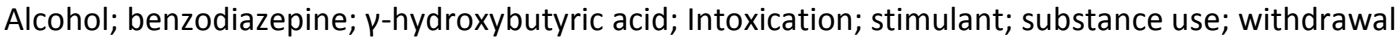

\section{Key points}

- Intoxication and withdrawal syndromes are common

-Knowledge about the clinical features of specific intoxication and withdrawal syndromes helps to predict the likely clinical course

- Central nervous system depressants are associated with medically dangerous withdrawal syndromes

-Identification of dependence is essential to identify patients at potential risk of a withdrawal syndrome

- Clinical risks can be prioritized by identifying broad clinical syndromes

-A collaborative and empathic approach can greatly reduce distress and improve outcomes 
Introduction

Many individuals choose to use substances, usually in a recreational capacity with limited associated harms. Substances can be legal or illicit, or fall in the grey area of novel psychoactive substances (NPSs) and pharmaceuticals taken outside medical supervision.

Patients present to general hospitals with direct consequences of their substance use or for unrelated reasons but require management of their co-morbid substance use. Patients may not disclose their use for fear of judgement, so clinicians should routinely assess for substance use. Failure to do so can lead to avoidable harm to the patient and others.

Intoxication and withdrawal syndromes are common presentations in acute medicine. Each substance or group of substances has characteristic syndromes including anticipated time frames for onset and resolution following last use. Knowledge of these features can guide management. NPSs present a greater diagnostic challenge as knowledge is more limited. However, many share common group features, which can guide initial assessment. Some patients use more than one substance (polysubstance use), which complicates identification and management of clinical syndromes.

This article presents an initial approach to clinical problems in the acute medical setting. It is not exhaustive and does not replace a full medical assessment. The pharmacology of individual substances (including NPSs) and specific management of acute intoxication and toxicity is covered elsewhere [] (publisher please put link to Poisoning chapter). ${ }^{1}$ Other reviews cover specific drugs in some detail. ${ }^{2,3}$ The National Poisons Information Service provides the most up-to-date information on their TOXBASE ${ }^{\circledR}$ website (https://www.toxbase.org).

\section{Terminology}

Detailed assessment and characterization of substance use is not required acutely. However, identifying a dependent pattern of use (Table 1 ) is key as it indicates individuals at risk of withdrawal.

\section{Substance use history}

A comprehensive history is required but may not be immediately forthcoming because of the patient's physical or mental state.

A collateral history should be obtained from family, friends, bystanders, paramedics and old notes. Consult other health professionals involved in the patient's care, for example the general practitioner and community mental health team where possible. Obtain a further history and review the initial information at the subsequent assessment. The history should be matched to the clinical examination findings, with consideration of objective tests such as a breathalyser or urine/serum drug testing. To avoid omission, questions should be asked specifically about each substance group (e.g. alcohol, stimulants, cannabis) and the following recorded for each:

-route of use

-time and amount of last use (to anticipate onset/resolution of intoxication and withdrawal syndromes)

- quantity, frequency and pattern of use (over last week or month)

- dependent features

-history of withdrawal and complications, such as seizures, delirium and psychosis

-context of use to identify associated risks, for example clubbing and high-risk sexual behaviour -co-morbidity including psychiatric.

\section{Quantifying substance use}

This is challenging as terminology may be unfamiliar to clinicians and frequently changes. Illicitly obtained drugs also vary in strength and purity, frequently containing fillers or adulterants. Patients can be reluctant to disclose their level of use or over-report it through fear of withdrawal being undertreated. There is no practical and reliable way to reconcile these issues. Record what is reported and regularly reassess the patient.

A simple way to express quantities is in terms of the cost, frequency of use or number of pills, for example $f 50$ per day, or four injections per day. Some substances can be quantified more accurately:

-alcohol in units

-benzodiazepines in diazepam equivalents $(\mathrm{mg})$

- nicotine as pack-years or number of cigarettes smoked

- cannabis as the number of joints or bongs, or in grams

-injectables in grams or points (one-tenth of a gram). 


\section{Substance use assessment}

Full 'ABCDE' assessment is essential. Clinical assessment should be dynamic, and significant changes in the patient's condition should prompt repeat assessment. Observation and frequent monitoring by nursing staff is required. The use of drug screening is imperfect; for example, it cannot detect NPSs, and the properties of available tests vary by location. However, it may be able to provide important objective evidence. The presence of 'track marks' at injection sites can be an important clue to substance use.

Many substance use presentations fall into one of two broad clinical scenarios: the sedated patient and the agitated patient. Both range in severity from mild to severe. This division is overly simplistic but prioritizes the management of key clinical risks.

\section{The sedated patient}

Sedation can indicate central nervous system (CNS) depressant intoxication or potentially the crash phase of stimulant withdrawal. Other toxicological or medical causes should also be considered.

The management priorities checklist is:

1. airway compromise

2. respiratory depression

3. cardiac arrhythmia

4. seizures

5. fluid and electrolyte abnormalities

6. Wernicke-Korsakoff syndrome.

\section{The agitated patient}

This can indicate a CNS depressant withdrawal syndrome, stimulant intoxication, serotonin syndrome (especially if stimulants have been used in conjunction with a serotonergic drug, e.g. selective serotonin reuptake inhibitor, tramadol), cannabis intoxication or withdrawal, or nicotine withdrawal. Alcohol, benzodiazepine and $\gamma$-hydroxybutyric acid (GHB) withdrawal syndromes are medically dangerous and require specific treatments to reduce morbidity and mortality. Opioid withdrawal is unpleasant but not usually lifethreatening.

The management priorities checklist is:

1. cardiac arrhythmia

2. cardiac ischaemia

3. seizures

4. serotonin syndrome

5. fluid and electrolyte abnormality

6. behavioural disturbance

7. Wernicke-Korsakoff syndrome.

Management of specific withdrawal syndromes and other key clinical issues (Table 2)

Alcohol

- Use a long-acting benzodiazepine (diazepam, chlordiazepoxide). ${ }^{3}$ This should be used with caution in severe respiratory or liver disease, possible head injury and stroke. Use oxazepam instead (as it is short-acting and renally excreted).

- In general hospitals, a fixed-dose regimen is recommended. ${ }^{3}$

- Monitor using the Clinical Institute Withdrawal Assessment for Alcohol (see Toxbase ${ }^{\circledR}$ ).

- Correct dehydration and replace electrolytes.

- If patients cannot take oral benzodiazepines, use a parenteral preparation, for example intravenous midazolam, but monitor the patient in a high-care environment. Intramuscular lorazepam is an alternative. Aim for light sedation from which patient is readily roused.

- For hallucinations, diazepam is first-line treatment; if there is no response, add olanzapine 5-10 mg orally.

- $\quad$ For primary and secondary prevention of seizures, use diazepam or lorazepam. ${ }^{3}$

\section{Wernicke's encephalopathy}

- All patients should be given prophylactic thiamine. 
- Give thiamine before glucose, as a carbohydrate load in the context of thiamine deficiency risks Wernicke's encephalopathy.

- If there is a high risk of Wernicke's encephalopathy (e.g. malnourished, unwell), give Pabrinex ${ }^{\circledR}$ one pair of ampoules intramuscularly or intravenously once daily for 3-5 days or until no further improvement is seen. ${ }^{3}$

- For suspected or established Wernicke's encephalopathy, give Pabrinex ${ }^{\circledast}$ two pairs of ampoules three times a day for $3-5$ days), followed by one pair of ampoules once daily for a further $3-5$ days depending on the response. ${ }^{3}$

\section{Benzodiazepines}

The risk of withdrawal on abrupt cessation increases after 4-6 weeks' regular use. It is dose-dependent but can occur at low doses. In stable, therapeutic dependence, the current prescription should be continued unless there is a clinical reason to change it. Detoxification is not recommended in the context of acute illness. In unstable use, if there is risk of a withdrawal syndrome, stabilize patients on one long-acting benzodiazepine (diazepam) while in hospital at $40 \%$ of their regular dose or $80 \mathrm{mg} /$ day (whichever is lower). Reported benzodiazepine use can all be converted into diazepam equivalents.

\section{$\boldsymbol{\gamma}$-Hydroxybutyric acid}

Use a benzodiazepine (diazepam) with or without baclofen ${ }^{3}$ to manage withdrawal. Seek specialist advice if the unit does not manage this routinely.

\section{Opioids}

Patients with opioid tolerance require higher doses of opioid analgesic drugs to achieve reasonable pain relief. Repeated requests for analgesia or specifically for opioid drugs beyond what would be expected from the clinical circumstances can indicate a substance use disorder. It is safe to provide higher doses to treat pain if the patient is reviewed regularly and monitored for evidence of toxicity. If substitution treatment is prescribed, this should be viewed as managing the opioid dependence; pain should be treated separately as for other patients acknowledging their altered tolerance. Seek specialist advice, especially with buprenorphine.

If patients are opioid-dependent, not already on opioid substitution treatment (OST) and need to remain in hospital for an extended period, substitution therapy may be needed to manage detoxification or prevent withdrawal while other medical conditions are treated. This requires specialist input from a clinician with experience in methadone or buprenorphine prescribing.

Opioid withdrawal is uncomfortable but not usually life-threatening, whereas opioid toxicity can be. Never prescribe OST until the prescribed dose and last dosing details have been confirmed with the prescriber and dispensing point. Adjustments may be required because of missed doses or the current clinical situation. However, OST should not be stopped because someone is in hospital. This is cruel and compromises their other healthcare needs. Have a very low threshold for seeking specialist advice if you do not regularly prescribe methadone and buprenorphine. In the interim, reassure the patient that you will manage their withdrawal symptomatically (Table 3 ).

\section{Nicotine}

Dependence is common and frequently co-morbid with other substance use. Cannabis is often taken mixed with nicotine, so consider both withdrawal syndromes together. The mainstay of treatment in hospital is nicotine replacement therapy. This is most effective as dual therapy with a patch for continuous treatment alongside a breakthrough product to manage cravings, such as an inhalator, gum or lozenges. Prescribe patches at night so peak effects occur by morning, when most smokers have the greatest cravings.

\section{Stimulants, cannabinoids and other substances}

Withdrawal is not usually medically dangerous, and specific pharmacological treatment is not required. Nonpharmacological strategies should be maximized where possible. However, it may be necessary or helpful to treat certain symptoms, especially if the patient requires other treatment and those symptoms are forming a barrier. All treatments should be short term, regularly reviewed and not continued after discharge without specialist advice and follow-up. The lowest possible doses should be used. See figure 4 for suggestions. 
This is an essential part of the assessment process that should focus on screening for anxiety, affective symptoms, psychotic symptoms, delirium and thoughts to harm the self or others. Psychiatric symptoms can reflect an acute manifestation of a substance use disorder, an unrelated organic pathology or an underlying psychiatric disorder that can be worsened, triggered or unmasked by acute intoxication or withdrawal. This can be difficult to determine and require further assessment once the acute syndrome has subsided. Seek psychiatric advice if the symptoms are severe or inconsistent with the expected clinical syndrome, or if initial treatment is ineffective.

\section{Risk assessment}

Consider any risks to children, occupational and driving risks, domestic violence and specific risks associated with the method or context of drug use, for example blood-borne viruses and sexual health issues.

\section{Working with patients}

This patient group can be challenging. They can be anxious, agitated, confused or angry. This can be a symptom of an acute syndrome but can also represent particular attachment styles and interpersonal difficulties that are more prevalent in substance use populations. Many individuals have experienced adversity or trauma such as childhood abuse. These previous experiences, often involving authority figures, can make their experience of healthcare more distressing as they are frequently interacting with persons in positions of authority, such as doctors and nurses. Many people feel vulnerable and out of control when they are ill and in hospital, and this experience can be heightened in this patient group.

Good communication is vital. Take the time to explain the likely course of the symptoms and acknowledge distress and frustration. Be up-front and honest about the fact that although treatments reduce discomfort, they may not eradicate all symptoms, as this may not be safe. For example, higher doses of benzodiazep[ines can cause respiratory depression Explain what treatments will be provided and how often, and what patient can expect to achieve. A collaborative, empathic and non-judgemental approach goes a long way. It can even reduce symptoms that can be worsened by stress. However, this can be accompanied by clear boundaries and an expectation that patients will try to work with staff as staff try to work with patients.

Clear risks are sometimes posed to the self or others. Maintaining the safety of the individuals, other patients and staff is always a priority. If there is evidence of risk to self, the level of intention, specific plans and availability of means should be assessed. Consider the need for direct observation, the removal of means and one-to-one nursing. If patients are very aggressive or threatening, consider involving security staff or the police.

\section{Future treatment}

Any contact with healthcare professionals represents an opportunity to bring about behavioural change. In non-dependent substance use, perform a simple brief intervention. In more severe or dependent substance use, it can be helpful to involve specialist teams to deliver more specialist interventions and plan follow-up care. 
Table 1 International Classification of Diseases, 10th edition, definitions

\begin{tabular}{|c|c|}
\hline & Definition \\
\hline Substance use dependence & $\begin{array}{l}\text { A cluster of behavioural, cognitive and physiological phenomena that develop } \\
\text { after repeated substance use and include three or more of the following in } 12 \\
\text { months: } \\
\text { 1. } \quad \text { Impaired capacity to control substance use } \\
\text { 2. Physiological withdrawal state } \\
\text { 3. } \quad \text { Evidence of tolerance to the effects of a substance } \\
\text { 4. } \quad \text { Preoccupation with substance use to the detriment of other activities } \\
\text { 6. } \quad \text { Persistent substance use despite clear evidence of harmful } \\
\text { consequences }\end{array}$ \\
\hline Acute intoxication & $\begin{array}{l}\text { A condition that follows the administration of a psychoactive substance, } \\
\text { resulting in disturbances in level of consciousness, cognition, perception, affect } \\
\text { or behaviour, or other psychophysiological functions and responses. } \\
\text { Disturbances are directly related to the acute pharmacological effects of the } \\
\text { substance and resolve with time with complete recovery except where tissue } \\
\text { damage or other complications have arisen }\end{array}$ \\
\hline Withdrawal state & $\begin{array}{l}\text { A group of symptoms occurring on absolute or relative withdrawal of a } \\
\text { psychoactive substance after persistent use. The onset and course of } \\
\text { withdrawal state are time limited and are related to the type of psychoactive } \\
\text { substance and the dose being used immediately before the cessation or } \\
\text { reduction of use. Withdrawal states may be complicated by the presence of } \\
\text { additional features e.g. delirium, seizures }\end{array}$ \\
\hline
\end{tabular}


Table 2 Clinical features of specific withdrawal syndromes

\begin{tabular}{|c|c|c|}
\hline Substance & Withdrawal syndrome (time frames relate to last use) & Specific risks \\
\hline \multicolumn{3}{|l|}{ CNS depressants } \\
\hline Alcohol & $\begin{array}{l}\text { Onset 6-24 hours (seizures 6-48 hours, delirium tremens } \\
\text { at 2-5 days); peaks } 24-48 \text { hours; duration 5-7 days } \\
\text { Features: tremor, sweating, nausea, retching or vomiting, } \\
\text { tachycardia, hypertension, psychomotor agitation, } \\
\text { headache, insomnia, malaise or weakness, transient } \\
\text { visual, tactile or auditory hallucinations or illusions, } \\
\text { seizures }\end{array}$ & $\begin{array}{ll}- & \text { Seizures }(5 \%) \\
\text { - } & \text { Delirium tremens } \\
& (5 \%) \\
\text { - } & \text { Wernicke-Korsakoff } \\
& \text { syndrome }\end{array}$ \\
\hline Benzodiazepines & $\begin{array}{l}\text { Depends on half-life of drug (and metabolites) } \\
\text { Long-acting, e.g. diazepam: onset 2-7 days; peak 7-10 } \\
\text { days; duration up to } 8 \text { weeks } \\
\text { Short-acting, e.g. lorazepam: onset 1-2 days; peak 2-5 } \\
\text { days; duration up to } 4 \text { weeks } \\
\text { Features: tremor, nausea, vomiting, tachycardia, postural } \\
\text { hypotension, psychomotor agitation, headache, insomnia, } \\
\text { malaise or weakness, transient visual, tactile or auditory } \\
\text { hallucinations or illusions, paranoid ideation, seizures }\end{array}$ & $\begin{array}{ll} & \text { Delirium } \\
\text { - } & \text { Seizures }\end{array}$ \\
\hline GHB & $\begin{array}{l}\text { Onset from } 30 \text { minutes; duration 3-21 days } \\
\text { Features: insomnia, tremor, confusion, nausea, vomiting, } \\
\text { tachycardia, hypertension, agitation, seizures, myoclonic } \\
\text { jerks and hallucinations }\end{array}$ & $\begin{array}{ll}\text { - } & \text { Agitated delirium } \\
\text { - } & \text { Seizures }\end{array}$ \\
\hline Opioids & $\begin{array}{l}\text { Depends on half-life of drug } \\
\text { Heroin (short-acting): onset 6-24 hours after last dose; } \\
\text { peak 24-48 hours; duration 5-10 days } \\
\text { Methadone (very long-acting): onset 36-48 hours after } \\
\text { last dose; peak - lower severity than heroin; duration 3-6 }\end{array}$ & \\
\hline
\end{tabular}




\begin{tabular}{|c|c|c|}
\hline & $\begin{array}{l}\text { weeks } \\
\text { Features: craving for an opioid drug, rhinorrhoea or } \\
\text { sneezing, lacrimation, muscle aches or cramps, nausea or } \\
\text { vomiting, diarrhoea, pupillary dilatation, piloerection or } \\
\text { recurrent chills, tachycardia or hypertension, yawning, } \\
\text { restless sleep }\end{array}$ & \\
\hline \multicolumn{3}{|l|}{ Stimulants } \\
\hline Nicotine & $\begin{array}{l}\text { Onset within hours of the last cigarette; peak 24-72 } \\
\text { hours; duration 2-4 weeks } \\
\text { Features: craving; malaise or weakness, anxiety, dysphoric } \\
\text { mood, irritability or restlessness, insomnia, increased } \\
\text { appetite, increased cough, mouth ulceration, difficulty } \\
\text { concentrating }\end{array}$ & \\
\hline $\begin{array}{l}\text { Other stimulants, e.g. } \\
\text { cocaine, MDMA, } \\
\text { amphetamine, } \\
\text { methamphetamine }\end{array}$ & $\begin{array}{l}\text { Occurs in three phases: } \\
\text { 1. Crash phase } \\
\text { Onset 12-24 hours; duration 2-4 days } \\
\text { Features: fatigue, hypersomnia, agitation, irritability, } \\
\text { dysphoria } \\
\text { 2. Withdrawal phase } \\
\text { Onset 2-4 days (amphetamine), 1-2 days (cocaine) } \\
\text { Peak 7-10 days (amphetamine), 4-7 days (cocaine) } \\
\text { Duration 2-4 weeks (amphetamine), 1-2 weeks (cocaine) } \\
\text { 3. Extinction phase } \\
\text { Features: dysphoric mood, lethargy and fatigue, } \\
\text { psychomotor retardation or agitation, craving, increased } \\
\text { dreams }\end{array}$ & $\begin{array}{l}\text { - Cardiac problems } \\
\text { (ischaemia, Acute } \\
\text { Coronary Syndrome, } \\
\text { arrhythmia) } \\
\text { - } \quad \text { Psychosis - may not } \\
\text { be apparent in the } \\
\text { crash phase } \\
\text { - Suicidal thoughts } \\
\text { - } \quad \text { Serotonin syndrome } \\
\text { Dilutional } \\
\text { hyponatraemia and } \\
\text { hyponatraemic } \\
\text { encephalopathy }\end{array}$ \\
\hline
\end{tabular}




\begin{tabular}{|l|l|c|}
\hline & Withdrawal features subside over weeks to months & \\
\hline Cannabinoids & $\begin{array}{l}\text { Onset within 24 hours; peak 4-7 days; duration 1-2 } \\
\text { weeks. Symptoms can persist for around 1 month }\end{array}$ & $\bullet$ Psychosis \\
& $\begin{array}{l}\text { Features: anxiety, irritability, tremor, sweating, muscle } \\
\text { aches }\end{array}$ & \\
\hline $\begin{array}{l}\text { Hallucinogens, e.g. } \\
\text { LSD }\end{array}$ & No specific withdrawal syndrome described & $\begin{array}{l}\text { Ketamine-related } \\
\text { urological syndrome }\end{array}$ \\
\hline $\begin{array}{l}\text { Dissociatives, e.g. } \\
\text { ketamine }\end{array}$ & No specific withdrawal syndrome described & \\
\hline
\end{tabular}


Table 3 Symptomatic management opioid withdrawal

\begin{tabular}{|c|c|}
\hline Symptoms & Suggested treatments \\
\hline Muscle aches/pains & Paracetamol 1000 mg, every 4 hours p.r.n. (max 4000 mg in 24 hours) \\
\hline Nausea & $\begin{array}{l}\text { Metoclopramide } 10 \mathrm{mg} \text {, three times a day p.r.n. or } \\
\text { Prochlorperazine } 5 \mathrm{mg} \text {, three times a day p.r.n. }\end{array}$ \\
\hline Abdominal cramps & Hyoscine $20 \mathrm{mg}$, every 6 hours p.r.n. \\
\hline Diarrhoea & Loperamide 2 mg p.r.n. \\
\hline Sleeplessness & Temazepam $10-20 \mathrm{mg}$ at night \\
\hline Agitation or anxiety & Diazepam 5 mg four times a day p.r.n. \\
\hline Restless legs & Diazepam (as above) \\
\hline Sweating or agitation & $\begin{array}{l}\text { Clonidine } 75 \mu \mathrm{g} \text { every } 6 \text { hours (ensure blood pressure }>90 \mathrm{mmHg} \text { systolic or }>50 \mathrm{mmHg} \\
\text { diastolic and heart rate }>50 \mathrm{bpm} \text { ) }\end{array}$ \\
\hline
\end{tabular}

Table 4 Symptomatic management of other withdrawal symptoms

\begin{tabular}{|l|l|}
\hline Symptom & Medication \\
\hline Psychotic symptoms & Olanzapine \\
\hline Low mood & $\begin{array}{l}\text { Do not start an antidepressant in the acute } \\
\text { phase }\end{array}$ \\
\hline Insomnia & Benzodiazepines, zopiclone, promethazine \\
\hline Restlessness, anxiety, irritability & Diazepam \\
\hline Stomach pains & Hyoscine (Buscopan ${ }^{\circledR}$ ) \\
\hline Pain, headaches & Paracetamol, ibuprofen \\
\hline Nausea & Promethazine, metoclopramide \\
\hline
\end{tabular}




\section{Key references}

1. Hill SL, Thomas SHL. Drugs of abuse. Medicine, 2016; 44(3): 160-9.

2. Lingford-Hughes AR, Welch S, Peters L, Nutt DJ; British Association for Psychopharmacology, Expert Reviewers Group. BAP updated guidelines: evidence-based guidelines for the pharmacological management of substance abuse, harmful use, addiction and comorbidity: recommendations from BAP. J Psychopharmacol, 2012; 26(7): 899-952.

3. Novel Psychoactive Treatment UK Network (NEPTUNE). Guidance on the Management of acute and chronic harms of club drugs and novel psychoactive substances. London: NEPTUNE, 2015. 